Journal of Computer Science 8 (4): 585-590, 2012

ISSN 1549-3636

(C) 2012 Science Publications

\title{
Implementation of Line Stability Index for Contingency Analysis and Screening in Power Systems
}

\author{
Subramani, C., Subhransu Sekhar Dash, Vivek Kumar and Harish Kiran \\ Department of EEE, SRM University Chennai, Tamilnadu, India
}

\begin{abstract}
Problem statement: Estimating the margin in the loadability of the power system is essential in the real time voltage stability assessment. Voltage stability is currently one of the most important research areas in the field of electrical power system. In power system operation unpredictable events is termed as contingency and may be caused by line outage in the system which could lead to entire system instability. Voltage stability analysis and contingency analysis are would be performed in a power system by evaluating the derived voltage stability index. Approach: Voltage Stability Index $\mathrm{L}_{\mathrm{mn}}$ can be useful for estimating the distance from the current operating point to voltage collapse point. The index can either reveal the critical bus of a power system or the stability of each line connected between two buses in an interconnected network or evaluate the voltage stability margins of a system. Results: Flexible Alternating Current Transmission Systems (FACTS) devices have been proposed as an effective solution for controlling power flow and regulating bus voltage in electrical power systems, resulting in an increased transfer capability, low system losses and improved stability. However to what extent the performance of FACTS devices can be brought out highly depends upon the location and the parameters of these devices. Unified Power Flow Controller (UPFC) is the most promising FACTS device for power flow control. Conclusion/Recommendations: The performance of this index is presented and the effectiveness of the analyzed methods is demonstrated through simulation studies in IEEE 14 bus reliability test systems.
\end{abstract}

Key words: Loading margin, voltage stability assessment, contingency analysis, voltage collapse, voltage stability index, UPFC device, stability enhancement

\section{INTRODUCTION}

Due to ever increasing load demand, power utilities are now forced to increase the utilization of existing transmission facilities. It is quite difficult to construct new lines due to environmental and economic considerations. As power systems become more complex and heavily loaded, along with economical and environmental constraints, voltage instability become an increasingly serious problem, loading systems to operate close to their limits. The problem related to voltage instability has become a major concern for secure operation of many power systems. This has necessitated the implantation of techniques for analysing and defecting voltage collapse in bus bar or lines prior to its occurrence. Voltage stability is concerned with the ability of a power system to maintain acceptable voltages at all nodes in the system under normal condition and after being subject to a disturbance (Kundur et al., 2004; Wiszniewski, 2007; Sode-Yome et al., 2007; Zhang et al., 2007). The main cause of voltage collapse may be due to the inability of the power system to supply the reactive power or an excessive absorption of the reactive power by the system itself. The continuous sequences of voltage instability leads to voltage collapse and ended in total blackout of the power station. During the last decades, the voltage stability problem has been given more attention primarily due to number of stability accidents that occurred in some countries. Some well known examples of voltage instability incidents were in France, Belgium, Sweden, Germany and Japan and in USA. Voltage collapse occurs when a system is heavily loaded and unable to maintain its generation and transmission schedule, observed by sudden decline or sag in system wide voltage. This change in voltage is so rapid that voltage control devices may not take corrective actions rapidly enough to prevent cascading blackouts. It is important for the operators and planners to find out the limit point of voltage instability. Therefore finding a voltage stability index has become an important task for voltage stability studies. A line stability index is proposed to aiming to detect the system loadability (Feurte-Esquivel and Acha, 1997).

Corresponding Author: Subramani, C., Department of EEE, SRM University Chennai, Tamilnadu, India 
These indices provide reliable information about proximity of voltage instability in a power system. Usually their values change from 0 (no load) to 1(voltage collapse). Line stability indices determine the weakest line in the system and to evaluate the voltage stability condition.

Unified Power Flow Controller (UPFC) is a versatile FACTS's device which can independently or simultaneously control the active power, the reactive power and the bus voltage to which it is connected. This controller offers substantial advantages for the static and dynamic operation of power system (Hingorani, 1998; Ongskul and Jirapong, 2005). However, to achieve such functionality, it is important to determine the optimal location of this device to be installed in power system with appropriate parameters setting. Since UPFC can be installed in different locations, its effective will be different. Therefore, we will face the problem of where we should install the UPFC. For this reason, some performance indices must be satisfied. The following factors can be considered in the selection of the optimal installation and the optimal parameters setting of multiple UPFCs: The topology of the system, the stability margin improvement, the power transmission capacity increasing and the power blackout prevention.

This study introduces the application of line stability index for the optimal allocation multiple shunt FACTS devices: Unified Power Flow Controller (UPFC), in order to improve voltage profile, minimizing power system total loss and maximizing system loadability.

Also a lot of work has been done in the contingency analysis area. Different contingency selection methods can be found in (Sudersan et al., 2004). Operation scheme of FACTS devices to enhance the power system steady-state security level considering a line contingency analysis is suggested in (Sudersan et al., 2004). A method for contingency selection and security enhancement of power systems by optimal placement of FACTS devices using $\mathrm{L}_{\mathrm{mn}}$ is presented here.

Attention is required to ensure that the voltage stability margin of the power system is above a desired level. It computes using simple Fast De-coupled Load Flow (FDLF), the state of a power system. If the power system collapses, then additional capacitor that needs to be switched on is computed by an iterative procedure (Arunagiri and Venkatesh, 2004). Increase the power transfer capability of transmission systems, minimize the transmission losses, support a good voltage profile and retain system stability under large disturbances. The study includes a detailed mathematical analysis of the impact of the shunt compensator on the power flow; investigation of the system constraints and their effects on the static compensator control; in addition simulation of static compensator to control a transmitted active power flow on the transmission line. The voltage could be kept constant independent of the loads with static compensator. The results show clearly the applicability of the proposed control scheme which is acceptable for the static compensator (Al-Husban, 2009).

The application of hybrid particle swarm optimization technique to find optimal location of unified power flow controller to achieve optimal power flow. Simulations are performed IEEE bus system for optimal location of UPFC and the results obtained are encouraging and will be useful in electrical restructuring (Taher and Tabei, 2008). Static Synchronous Compensator (STATCOM) and Static Synchronous Series Compensator (SSSC) have been individually applied to improve stability of power system. The system with a STATCOM or a SSSC can increase damping of power system whereas the system with coordination of a STATCOM and a SSSC provides the best results of stability improvement (Kumkratug, 2011)

Problem statement and stability index: The purpose of $\mathrm{L}_{\mathrm{mn}}$ is to determine the point of voltage instability, the weakest bus in the system and the critical line referred to a bus. There are several indices based on bus and the line.The performance all these indices have been found to show high degree of accuracy and reliability. The line stability index Lmn is used for stability analysis in this study. Voltage stability analysis can be conducted on a system by evaluating the line stability index referred to a line. The value of the index which is closed to unity indicates that the respective line is closed to its stability limit (Shaheen et al., 2008). M.Mohavemmietal. derived a line stability index based on a power transmission concept in a single line. In this study, the line stability index referred to a line was formulated and given as:

$$
\frac{4 \mathrm{QrX}}{[|\mathrm{Vs}| \sin (\theta-\delta)]^{2}}=\mathrm{L}_{\mathrm{mn}} \leq 1.00
$$

Where:

$\mathrm{X}=$ Line reactance

$\mathrm{Q}_{\mathrm{r}}=$ Reactive power at the receiving end

$\mathrm{V}_{\mathrm{s}}=$ Sending end voltage

$\Theta=$ Line impedance angle

$\delta=$ The angle difference between the supply voltage and the receiving voltage 
Algorithm for Weak Bus Identification for FACTS Location

The following steps are implemented.

- Run the load flow program using Newton-Raphson method for the base case

- Evaluate the $\mathrm{L}_{\mathrm{mn}}$ value for every line in the system

- Gradually increase the reactive power at chosen load bus Calculate $L_{m n}$ Values for every load variation for all the lines

- The value of $\mathrm{L}_{\mathrm{mn}}$ close to 1.00 indicates that the particular line is close to its instability point which may lead to voltage collapse in the entire system

- Extract the line index that has the highest value; this line is called as the most critical line with respect to a load bus. Note the reactive power loading and voltage at the bus

- Choose another load bus repeat steps 1-5

- Extract the maximum reactive power loading for the maximum computable $\mathrm{L}_{\mathrm{mn}}$ for every test bus. It can be obtained from step5.The maximum Reactive Power loading is referred to as the maximum loadability of a Particular bus

- $\quad$ Sort the maximum loadability obtained from step 7 in ascending order. The Smallest maximum loadability is ranked the highest implying the Weakest bus in the system. This is the location for Stability enhancement

Contingency analysis and screening: In power system operation unpredictable events is termed as contingency. It may be caused by line outage in the system which could lead to entire system instability. Voltage stability analysis could be performed in a power system by evaluating the derived voltage stability index. The values of the voltage stability index would indicate the distance to voltage collapse for a given loading condition. These indices are taken as an instrument that will measure the stability condition and used to rank the contingencies in a power system. A high contingency ranking implies the severe effect of a particular contingency to the system. A load flow analysis is carried out prior to the computation of the voltage stability index and ranking of contingencies. The results obtained from the load flow analysis will be utilized for computed the voltage stability index and ranking of the contingencies.

Using the line stability index contingency analysis was carried out and a contingency table was developed from the results obtained from the simulation of each transmission line outage. The outage which resulted in a severe stability condition will be ranked high. From the contingency ranking table, the effect of breakdown at a line on voltage stability condition of a system could be determined. The contingencies tested were based on transmission line outage. Several cases are simulated in order to determine the contingency ranking.

\section{RESULTS}

The voltage stability analyses were performed on IEEE14 busbar test system. This system has 5 generator buses, 9 Load buses and 20 interconnected branches, as shown in Fig. 1. To validate the performance of the indicator, an IEEE 14 bus reliability test system is used. The reactive power at these buses increased gradually one at a time. For finding the maximum load and weak bus nine load buses namely bus $4,5,7,9,10,11,12,13$ and bus 14are investigate one by one. The results are tabulated below. From Table 1 we can find the maximum load, critical voltage and critical line. For example consider Bus no.14, it has the rank 1. From the base case increase the reactive power till the index value closes to 1 .

The maximum computable value of $\mathrm{L}_{\mathrm{mn}}$ obtained is 0.9999 for the line connected between buses 13 and 14 i.e. $\mathrm{L}_{19}$. The $\mathrm{L}_{\mathrm{mn}}\left(\mathrm{L}_{19}\right)$ value (0.9999) at this point is close to unity indicating that the system has reached its stability limit. At this point $\mathrm{L}_{19}$ is the most critical line with respect to bus 14 . The critical voltage of particular bus is 0.6626 p.u.

At the same time maximum reactive power loading for the maximum computable value of $\mathrm{L}_{\mathrm{mn}}$ (Bus No.14) is $73 \mathrm{MVar}\left(\mathrm{Q}_{\max }\right)$, beyond this limit violation will be experienced. From this result we can also found that Bus No. 5 has the highest maximum reactive power (375.38 MVar) and Bus No. 14 has the lowest maximum reactive power (73 MVar). This means that Bus No.5 is the healthy bus and Bus No. 14 is the weakest bus in the system. As the load on particular load bus increases, voltage on that load bus will decrease.

\begin{tabular}{lclllll}
\multicolumn{7}{l}{ Table 1: Maximum Laudability of load buses } \\
\hline Rank & $\begin{array}{l}\text { Bus } \\
\text { Num }\end{array}$ & $\begin{array}{l}\text { Q }_{\max } \\
\text { (MVAr) }\end{array}$ & $\begin{array}{l}\text { Voltage } \\
\text { (P.U) }\end{array}$ & $\begin{array}{l}\text { Critical } \\
\text { line }\end{array}$ & $\begin{array}{l}\text { Line } \\
\text { from-to }\end{array}$ & L $_{\text {mn }}$ \\
\hline 1 & 14 & 73.000 & 0.6626 & 19 & $13-14$ & 0.9999 \\
2 & 12 & 85.795 & 0.7686 & 18 & $12-13$ & 0.9999 \\
3 & 10 & 94.470 & 0.7180 & 8 & $4-9$ & 0.9999 \\
4 & 9 & 99.150 & 0.7852 & 8 & $4-9$ & 0.9999 \\
5 & 11 & 102.185 & 0.7326 & 10 & $6-11$ & 0.9999 \\
6 & 7 & 111.950 & 0.7600 & 13 & $7-8$ & 0.9999 \\
7 & 13 & 150.380 & 0.7413 & 12 & $6-13$ & 0.9999 \\
8 & 4 & 330.850 & 0.7956 & 6 & $3-4$ & 0.9999 \\
9 & 5 & 375.380 & 0.7722 & 5 & $2-5$ & 0.9999 \\
\hline
\end{tabular}




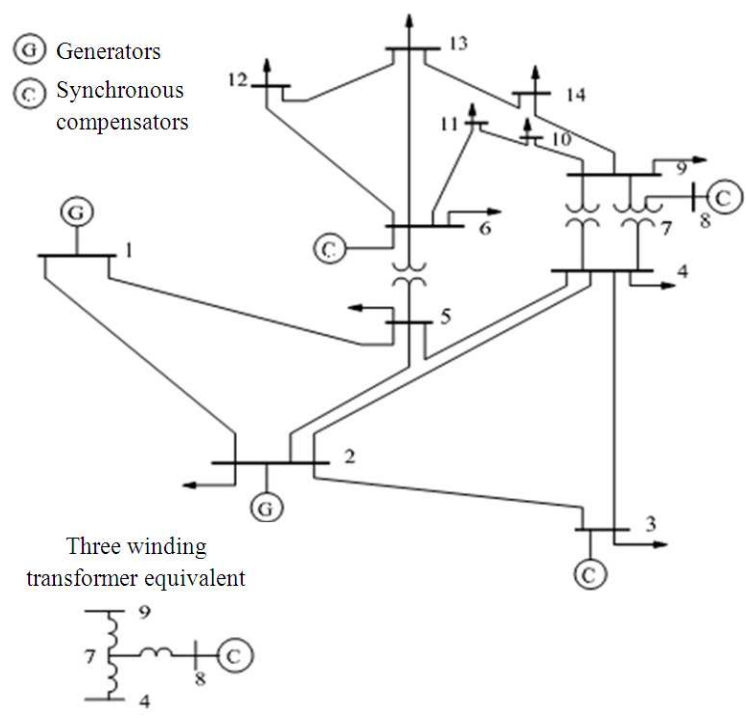

Fig. 1: IEEE-14 bus system

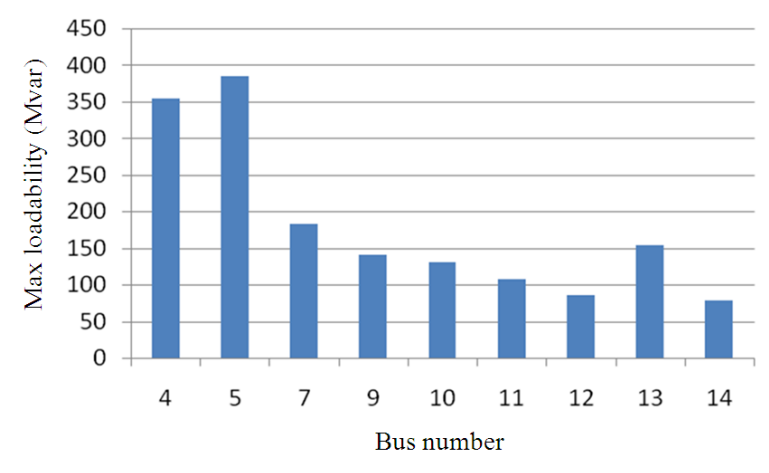

Fig. 2: Maximum Mvar for load buses

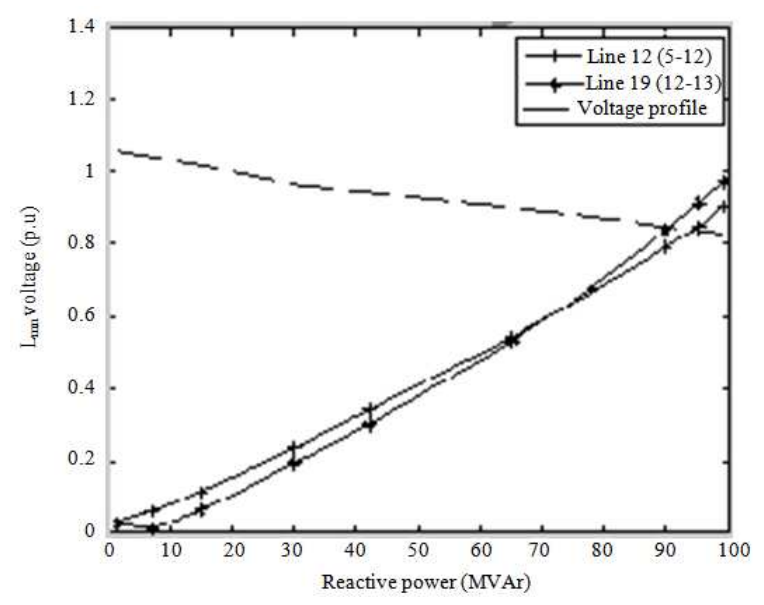

Fig. 3: Variation of voltage and index with load changes (bus 12)

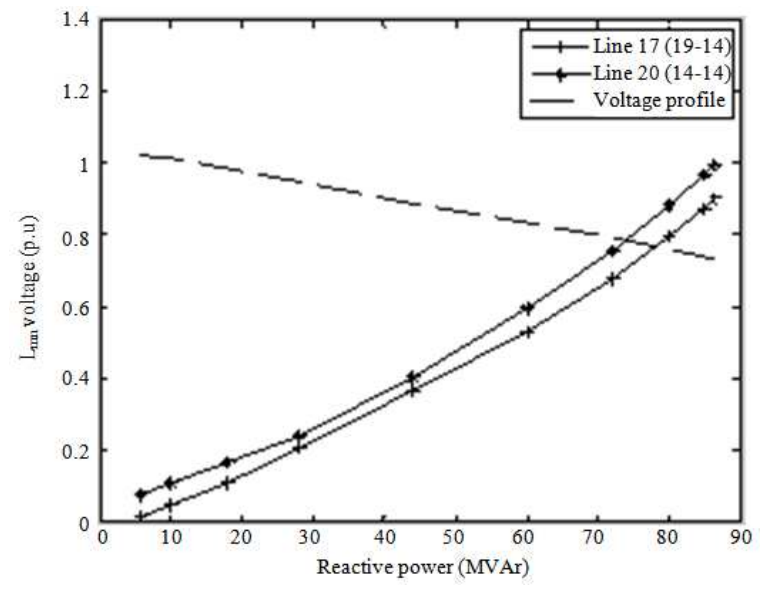

Fig. 4: Variation of voltage and index with load changes (bus 14)

For example for bus 4 at 30 MVar loading voltage is 0.9826 p.u, when load increased to maximum loading $330.85 \mathrm{MVar}$, the voltage is 0.7956 p.u., similarly, for bus 12 at 30 MVar loading voltage is 0.9188 p.u., when load to maximum loading $85.795 \mathrm{MVar}$, the voltage will be 0.7686p.u. Figure 2 shows the maximum loadability of all the load buses. The computed index variations and voltgae proile with increasing reactive power for the buses 12 and 14 are represented in Fig. 3 and 4 respectively.

Branch contingency analysis with reactive power changes in load buses: These indices are taken as an instrument that will measure the stability condition and used to rank the contingencies in a power system. A high contingency ranking implies the severe effect of a particular contingency to the system. Contingency ranking for different cases randomly selected were based on line stability values evaluated for each loading condition. The computation was performed by taking line outage 1 through 20 consecutively for each different case. The values of line stability indices highlighted in the table demonstrate the highest indices after being sorted in descending order.

The Branch outage contingency analysis is conducted at $50 \%$ of the loading condition at Bus 14 . From the table, it can be seen that line outage at line 17 is at the top of the list. Since it has caused voltage collapse in the system, when the line 15 is outage, the proposed line stability index is evaluated for each line in the system and the result yields the line stability index value for line 9 is the highest which is 0.8367 . It shows that line 20 is approaching its voltage stability limit. However, it can be seen that outage in line 17 gives the index value at line 20 is 1.000 , indicates voltage collapse has occurred in this line. 
J. Computer Sci., 8 (4): 585-590, 2012

Table 2: Result of branch outage contingency analysis

\begin{tabular}{lcccll}
\hline Bus No. & $Q_{\max }(\mathrm{MVAr})$ & CBO & Critical line & Critical voltage $(\mathrm{p} . \mathrm{u})$ & $\mathrm{L}_{\mathrm{mn}}$ \\
\hline 4 & 215.00 & 3 & $6(3-4)$ & 0.8443 & 0.9595 \\
5 & 164.81 & 1 & $2(1-5)$ & 0.8419 & 0.9574 \\
7 & 125.00 & 8 & $14(7-8)$ & 0.8247 & 0.9669 \\
9 & 71.94 & 15 & $9(4-9)$ & 0.7855 & 0.9775 \\
10 & 97.50 & 11 & $9(4-9)$ & 0.6015 & 0.9860 \\
11 & 52.00 & 11 & $18(10-11)$ & 0.5970 & 0.9782 \\
12 & 39.05 & 12 & $19(12-13)$ & 0.8154 & 0.9852 \\
13 & 57.00 & 13 & $19(12-13)$ & 0.7033 & 0.9615 \\
14 & 38.48 & 17 & $20(13-14)$ & 0.7020 & 0.9766 \\
\hline
\end{tabular}

CBO-Critical Branch Outage: Similar analysis was conducted for all other cases in order to determine which line outage would cause voltage collapse to occur in the system. From the table we can also analyses that the line which has the index value close to 1.00 which is the most critical line in that case and the line which has the index value greater than 1 means due to the outage of that line voltage collapse was occurred. Here when outage of 17 occurs then Line 20 is the most critical line. The top five severe branch outages with respect to bus 14 are tabulated and also the most critical line corresponding to the branch outages also mentioned. The line outage which caused the system to violate or resulted in system to be closest to its voltage stability limit is ranked the highest. For this case, it can be seen that line outage at line 17 is at the top of the list, since it has caused voltage collapse in the system. The over all result for the line outage contingency analysis of all the load buses in IEEE 14 bus sytem are reported in Table 2.

\section{DISCUSSION}

The weak bus identified from Voltage stability analysis is the suitable location for the FACTS device for Stability enhancement. So the bus 14 is the suitable location for stability improvement. By the performance of branch outage contingency analysis, the severe line outage was identified which is responsible for voltage collapse in the system. The branch 17 is the severe branch outage, since it has caused voltage collapse in the system. The line 20 has highest value of index when the branch 17 was outage.

So the line 20 is another suitable location for stability enhancement in 14 bus system. So it is to be noted that the bus number 14 and line 20 are the suitable locations for placing the UPFC under single contingency. After placing the UPFC the voltages at the load 14 is increased and the line stability index $\mathrm{L}_{\mathrm{mn}}$ was decreased. This results noted in Table 3. Hence the loading at bus 14 is increase to certain limit over the without FACTS device.
Table 3:Index Magnitude and Voltage profile with and without FACTS device

\begin{tabular}{|c|c|c|c|c|c|}
\hline \multirow[b]{2}{*}{$\begin{array}{l}\text { Branch } \\
\text { outage }\end{array}$} & \multirow[b]{2}{*}{$\begin{array}{l}\text { Critical } \\
\text { line }\end{array}$} & \multicolumn{2}{|c|}{ Without FACTS device } & \multicolumn{2}{|c|}{ With FACTS device } \\
\hline & & $\begin{array}{l}\mathrm{L}_{\mathrm{mn}} \\
\text { (Line) }\end{array}$ & $\begin{array}{l}\text { Voltage } \\
\text { (Bus 14) }\end{array}$ & $\begin{array}{l}\mathrm{L}_{\mathrm{mn}} \\
\text { (Line) }\end{array}$ & $\begin{array}{l}\text { Voltage } \\
\text { (Bus 14) }\end{array}$ \\
\hline$\overline{17}$ & 20 & 1.0000 & 0.5516 & 0.9057 & 0.8708 \\
\hline 15 & 9 & 0.8367 & 0.7646 & 0.5817 & 0.9146 \\
\hline 20 & 17 & 0.7695 & 0.7353 & 0.7169 & 0.9680 \\
\hline 8 & 9 & 0.5801 & 0.8228 & 0.4129 & 0.9645 \\
\hline 13 & 17 & 0.5312 & 0.8063 & 0.4689 & 0.9355 \\
\hline
\end{tabular}

\section{CONCLUSION}

The Voltage Stability line Index determines the maximum load that is possible to be connected to a bus in order to maintain stability before the system reaches its bifurcation point. Contingency ranking based on Contingency screening and ranking is one of the most important issues for security assessment in the field of power system operation. The application of line stability indices on IEEE14 bus testing system gave accurate results. The shown simulations result Table 1 indicate that the bus14 of IEEE 14 bus test system is considered the weakest bus in the system. And as reactive load on load bus increases, voltage margin will decrease as show in above result which leads to voltage instability, so it is required to enhance the voltage stability. Line indices provide accurate information with regard to the stability condition of the lines.

After placing the UPFC the voltages for all the load buses were increased and the line stability index $\mathrm{L}_{\mathrm{mn}}$ was decreased, means that loading on that particular load bus is increasable to certain limit over the without FACTS device under single contingency. So the steady state system is enhanced under single contingency.

\section{REFERENCES}

Al-Husban, A.N., 2009. An eigenstructure assignment for a static synchronous compensator. Am. J. Eng. Applied Sci., 2: $\quad 812-816 . \quad$ DOI: 10.3844/ajeassp.2009.812.816 
Arunagiri, A. and B. Venkatesh, 2004. Simulation of voltage stability and alleviation through knowledge based system. Am. J. Applied Sci., 1: 354-357. DOI: 10.3844/ajassp.2004.354.357

Feurte-Esquivel, C.R. and E. Acha, 1997. A Newtontype algorithm for the control of power flow in electrical power networks. IEEE Trans. Power Syst., 12: 1474-1480. DOI: 10.1109/59.627844

Hingorani, N.G., 1988. Power electronics in electric utilities: Role of power electronics in future power systems. Proc. IEEE, 76: 481-482. DOI: $10.1109 / 5.4432$

Kumkratug, P., 2011. Coordination of series and shunt flexible AC transmission system devices based voltage source converter for improving power system stability. Am. J. Applied Sci., 8: 495-498. DOI: 10.3844/ajassp.2011.495.498

Kundur, P., J. Paserba, V. Ajjarapu, G. Andersso and A. Bose et al., 2004. Definition and classification of power system stability IEEE/CIGRE joint task force on stability terms and definitions. IEEE Trans. Power Syst., 19: 1387-1401. DOI: 10.1109/TPWRS.2004.825981

Ongskul, W. and P. Jirapong, 2005. Optimal allocation of FACTS devices to enhance total transfer capability using evolutionary programming. Proceedings of the IEEE International Symposium on Circuits and Systems, May 23-26, IEEE Xplore Press, $\quad$ pp: 4175-4178. DOI: 10.1109/ISCAS.2005.1465551

Shaheen, H.I., G.I. Rashed and S.J. Cheng, 2008. Optimal location and parameters setting of UPFC based on GA and PSO for enhancing power system security under single contingencies. Proceedings of the IEEE Power and Energy Society General Meeting Conversion and Delivery of Electrical Energy in the 21st Century, Jul. 20-24, IEEE Xplore Press, Pittsburgh, PA., pp: 1-8. DOI: 10.1109/PES.2008.4596594
Sode-Yome, A., N. Mithulananthan and K.Y. Lee, 2007. A comprehensive comparison of FACTS devices for enhancing static voltage stability. Proceedings of the Power Engineering Society General Meeting, Jun. 24-28, IEEE Xplore Press, Tampa, FL., pp: 1-8. DOI: 10.1109/PES.2007.385687

Sudersan, A., M. Abdelrahman and G. Radman, 2004. Contingency selection and static security enhancement in power systems using heuristicsbased genetic algorithms. Proceedings of the 36th Southeastern Symposium on System Theory, Mar. 16-16, pp: 556-560. DOI: 10.1109/SSST.2004.1295720

Taher, S.A. and S.M.H. Tabei, 2008. A Multi-objective HPSO algorithm approach for optimally location of UPFC in deregulated power systems. Am. J. Applied Sci., 5: 835-843. DOI: 10.3844/ajassp.2008.835.843

Wiszniewski, A., 2007. New criteria of voltage stability margin for the purpose of load shedding. IEEE Trans. Power Syst., 22: 1367-1371. DOI: 10.1109/TPWRD.2006.886772

Zhang, J., J.Y. Wen, S.J. Cheng and J. Ma, 2007. A novel SVC allocation method for power system voltage stability enhancement by normal forms of diffeomorphism. IEEE Trans. Power Syst., 22: 1819-1825. DOI: 10.1109/TPWRS.2007.907538 